\title{
Understanding the Principles of Homeopathy on A Research Perspective
}

\author{
Eswara Das* \\ Department of Medical Research, Sarda Krishna Homeopathic Medical College, India
}

Submission: February 25,2019; Published: March 11, 2019

*Corresponding author: Eswara Das, Centre for Health Informatics-Government of India, India

\begin{abstract}
The practice of every medical system involves scientific theories and artistic approaches. Harmonious blend of science that are demonstrable with contemporary tools of investigation and its artistic application to understand the sick make that medical system rational therapeutics. Homeopathy originated as a new medical approach in early 18th century is based on definite scientific and artistic concepts. The system is based on seven principles/ theories, codified by Dr Hahnemann, its founder. The practice of homeopathy was well accepted by the public from the very inception due to safety of medicine and effectiveness. The popularity of homeopathy spread across the globe even during the life time of its founder. It was considered as one of the refined medical systems till about 1950s. With the advent of material science, questions started arising on the scientific basis of some of its principles and few started even perceiving the system as a fringe medicine. The most controversial principle is the drug dynamisation, wherein the original drug substance (even inert material) is diluted serially with water/ethanol/ milk sugar and treated through a process called potentization/ trituration. This is done at ultra-high dilution levels to 10-60, 10-400 or even higher. Homeopaths believe that the higher a remedy is dynamised, the therapeutic efficacy is greater. The justification proposed is that diseases primarily produce derangements in the life force and only a dynamised remedy could initiate a cure. The concept of ultra-high dilution through drug dynamisation is in violation of the physical law limiting the theoretically divisible limit of matter restricted to Avogadro's constant. Another contradiction is that while homeopathy advocate minimum dose to initiate a cure, biomedicine proposes quantifiable optimum dose. Mostly these two major contradictions put a question mark on the therapeutic supremacy homeopathy achieved over the last 250 years. Few even consider the curative results of sub molecular homeopathic remedies to a placebo effect.
\end{abstract}

In the recent past, there has been honest effort by the mainstream scientists to investigate the intricate and unorthodox principles of homeopathy in the light of modern knowledge of science. An analysis of the findings of such investigations shows that Dr Hahnemann, through his experimentation fortified the key concept of similia with three crucial principles that are experimentally verifiable with models of physics, chemistry, biophysics, biotechnology, Nano-technology, genetics or gene expressions. Out of these three the most controversial principle is drug dynamisation, wherein the ultra-high dilutions are used to effect therapeutic modulations. Several scientific investigations through physical, chemical and mathematical modelling have been carried out around the world with promising outcome on the nature of the ultra-high dilutions. Still lot of clarity is needed to make proper scientific modelling on these three basic concepts to undertake fundamental research. A conceptual frame work is proposed on the principles of homeopathy clearly demarcating as to which of them are researchable with modem tools of investigations and the artistic approaches used by the practitioners. An explorative exercise is also made to analyse various research outcome on drug dynamisation to establish the scientific basis of Homeopathy.

Keywords: Research; Fundamental principle; Basic research; Plausibility; Drug dynamization; Nanoparticles; Xenobiotics; Water memory; Placebo effect; Homeopathy

\section{Introduction}

Homeopathy is a distinctive medical specialty being practiced across the world. The system has blended well into the roots and traditions of many countries and play an important role in providing health care to a large number of people. It is widely used as a first line of treatment in many non- so- serious illnesses on a self-medication basis. It is also a primary care option for several serious illnesses through expert medical consultation. But, the strength of homeopathy lies in its evident effectiveness on certain clinical conditions for which there is less treatment options in other systems. Homoeopathy takes a holistic approach towards the sick through promotion of inner balance at mental, emotional, spiritual and physical levels. However, in spite of such therapeutic evidences, it is viewed as an unorthodox medical practice by its sceptics. To an extent there exist some doubt about the scientific basis of the system even among its young practitioners, mainly because of the consistent onslaught by few sceptics and also due to the inability of the profession to explain certain principles which remain unconventional to the yester 
years knowledge in science. In this context, it is interesting to analyse the principle that propound homeopathy as a scientific and artistic approach in medicine.

\section{Hahnemann, the Scientist who Lived Before His Time}

Dr Hahnemann (1755-1843), the founder of Homeopathy was more concerned to evolve a safe and effective therapeutic paradigm around the key concept of similia. The science was at its nascent stage. Vital force was still believed to essential for organic reactions in Chemistry [1], miasmatic theory of causation of diseases was prevalent [2]. The concept of drug proving on healthy human being was proposed by Albrecht von Haller [3]. With this background, Dr Hahnemann went on to codifying a new medical system with seven principles/ theories or doctrines after experimenting over a period of 15 years. He fortified the key concept with drug proving, drug dynamisation and individualisation as crucial to the simila concept. The inquisitive mind of Dr Hahnemann foresaw the scope of expanding these three principles to be experimented and explained with tools of scientific investigations. He further strengthened these concepts with four ancillary theories, namely chronic diseases (Miasm), vital force (vital principle), single medicine and minimum dose. Thus, his experiments starting from the famous peruvian bark trial and publication of Essay on a New Principle for Ascertaining the Curative Powers of Drugs in 1796 was the foundation of the key principle Similia. He expanded this concept further and converged his thoughts with more explanatory notes and gifted a wholesome medical system, that he called Homeopathy, by publishing the first edition of Organon of Medicine in 1810. Hahnemannian concepts on the principles of homeopathy could be summarised as follows Figure 1.

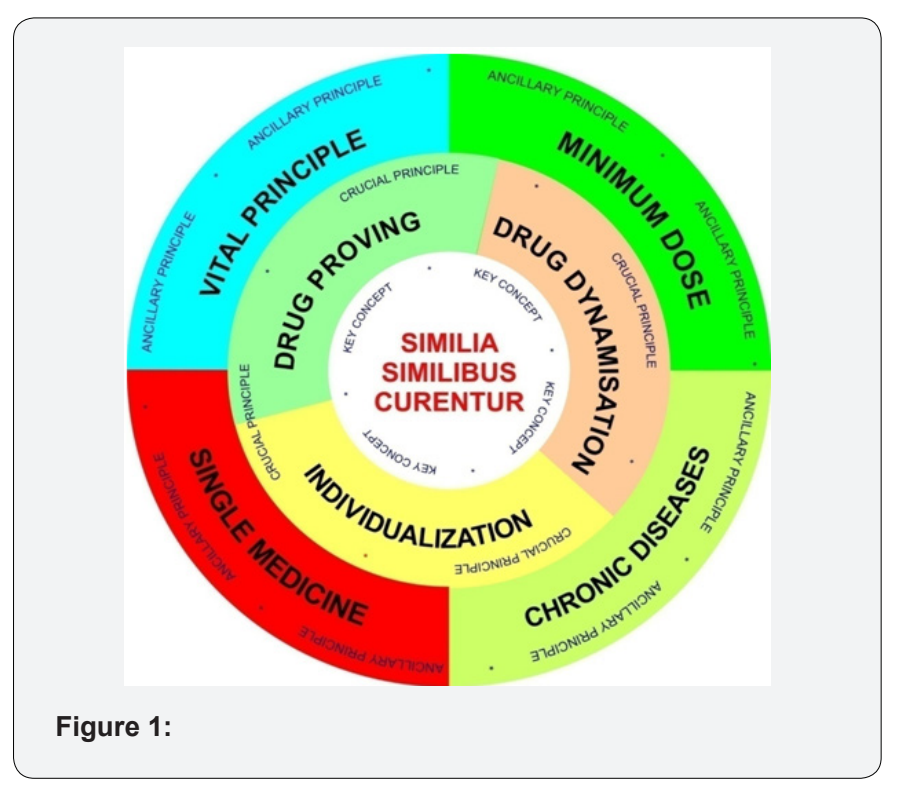

The key concept of Homeopathy is "similia similibus curantur", often known as Similia principle. This was a concept known in medicine from the time of Hippocrates or even in the ancient
Indian system of Ayurveda. On the basis of the peruvian bark experiment, Dr Hahnemann derived the first crucial principle of Homeopathy, namely, drug proving. He acknowledged the credit to the concept to Albrecht von Haller [3] (1708-1777) in the foot note to Aphorism 108 of Organon of Medicine.

\section{Drug Dynamisation and Ultra High Dilute Nature of Homeopathic Remedies}

Drug dynamisation is the most controversial of the concepts proposed by Hahnemann. He did not give any reference that led him to arrive on this concept. Historically, we know that Dr Hahnemann used the tincture of peruvian bark to experiment the concept of similia. Later he went on diluting the original material to reduce the drug toxicity, but he arrived on mathematically evolved sequential dilutions of decimal, centesimal and the millismal modelling with a method of successions/ titurations to enhance the pharamaco-dynamic properties of even inert substances that was unknown to the profession till that time. (There exists one method in Ayurveda, where in the root of Sida cordifolia (Kurunthotti in Malayam) is serially diluted with milk and stirred up about 100 times [4], known as Ksheerabala. The drug dynamisation has become so controversial because it defied the material scientific theories. The serial dilutions with water or ethanol and sucussion (drug dynamistion), takes away the resultant homeopathic potencies beyond the divisibility limit of matter as per Avogadro's constant, that stipulates the number of units in one mole of any substance (defined as its molecular weight in grams), equal to $6.022140857 \times 1023$. According to this concept, there won't be any matter of the original solute beyond the 23rd decimal potency or 12 th centesimal potency of homeopathic medicine. However, in homeopathic practice, the 30 th, 200 th or even 1000 th potencies are therapeutically used and claims to have higher the pharamaco-dynamic curative properties with the higher dynamised medicine. Thus, in homeopathy the therapeutic action of a remedy is inversely proportional to the quantity of the original drug substance. This is in contrast to the claim of the biomedicine, which asserts that the potent action of a drug is directly proportional to quantity of the drug substance.

Thus, the drug dynamisation, being the most controversial concept that labels homeopathy unorthodox by sceptics, it is important to analyse various developments on this particular concept. One of the earliest models on the scientific basis of homeopathic drug dynamisation is Hormesi, based on Arndt Schulz Law [5], named after Hugo Paul Friedrich Schulz and Rudolf Arndt, that says that every substance at small doses stimulate, moderate doses inhibit and in large doses kill. This implies that highly diluted pharmacologically active substances or poisons enhance life processes, while strong concentrations may inhibit these processes and even terminate life. This law has been demonstrated to be good in the case of many poisonous substances. Arndt-Schulz Law was proposed in about 1890 and 
was considered a major breakthrough on drug dynamisation by the advocates of Homeopathy. However, its applicability as a universal principle on ultra-high dilution did not get wider scientific approval.

In early 1970s Dr RR Sharma [6] brought out a correlation with another theory of Xenobiotics that was widely discussed in the field of science. Dr. Sharma has been a relentless researcher who worked to find plausible answers to the homeopathic concepts. He has the background of Biophysics, reasonable facilities to work on the subject as he was working in the Department of Biophysics at one of the premier medical institution in India and a lover of Homeopathic science. He postulated several concepts and published large number of scientific articles. Dr Sharma gives a comprehensive approach on the action of homeopathic medicines in ultra-high dilution on a vitalistic system through the neuro- endocrinal- reticuloendothelial axis. He substantiates that the ultra-high dilutions derived through drug dynamisation do have power to activate the biological system and postulates that all biological functions and phenomena in health, disease and cure are mediated by molecular mechanisms. We have heard lot about the water memory theory proposed by Dr Jacques Benveniste [7], Dr Rustom Roy [8] and a host of modern scientists. Dr Benveniste, a French immunologist published a paper in the journal Nature describing the action of very high dilutions of anti-Ig E antibody on the degranulation of human basophils. His findings supported the concept of ultra-high dilutions of Homeopathy. Biologists were puzzled by Benveniste's results, as only molecules of water, and no molecules of the original antibody, remained in these high dilutions. Benveniste concluded that the configuration of molecules in water was biologically active coining the term water memory for this hypothesis. Much later, in the nineties, Benveniste also asserted that this "memory" could be digitized, transmitted, and reinserted into another sample of water, which would then contain the same active qualities as the first sample. Though controversy erupted on this with the active support of the detractors of homeopathy, Benveniste refused to retract his controversial article, and he explained that the protocol used in these investigations was not identical to his own. Sadly, he died in 2004 without getting opportunity to prove his innovative theory.

Dr Rustom Roy, Professor at Pennsylvania State University was a leader in materials research. The basic principle of the water memory concept is that water can retain a memory of the substances it has been previously exposed to and can therefore maintain the properties of those substances, even after the physical substance is removed. The proponents of this theory consider water as a super-fluid or quantum fluid. This concept is quite active now and more and more scientists are working on this. This may explain the effects of homeopathic drugs well beyond Avogadro's number (12C or $24 \mathrm{X}$ ). This concept is also being researched with modern analytical procedures. Another model on the effect of homeopathic remedies in ultra-high dilutions has been demonstrated by various scientists in the recent past through Nano-precipitation of the original solute even on highly dynamised medicines. This has given a renewed enthusiasm to the scientists and even there is an effort to label Homeopathy as Nano medicine. While Prof. Anisur Rahman Khuda-Bukhsh of Kalyani University, et all demonstrates that the Nano particles initiate epigenetic modification of the DNA, Professor Jayesh Bellare, Indian Institute of Technology, Bombay, Dr ES Rajendran, Vinayaka Missions University, Paolo Bellavite, University of Verona and many others have isolated the nanoparticles from ultra-high dilutions of homeopathic remedies demonstrating presence of material substances, which was hitherto considered placebo. Many theories are postulated on the nature of homeopathic drug dynamisation and more researches are being carried out through biological, physical, chemical and mathematical models. The need of the hour is to invite the best of the brains in these areas to have a deeper exploration on these baffling concepts for better understanding on the action of remedies.

\section{Drug Proving}

Drug proving is demonstrable with existing scientific protocols as a hard science. More experimental evidences shall encapsulate the similia principle as a science based medicine. These are the areas of fundamental research, certainly lot more cutting-edge research is needed urgently to bring Homeopathy as the refined medical science. (Details on this concept shall be analysed in later articles) [9].

\section{Concept of Individualisation}

The individualisation that is practiced in homeopathy is an attempt to understand the patient. It is crucial to diagnose the patient with a deeper understanding on his/her constitution, temperament, presenting complaints, genetic makeup, personal, past and present histories etc. This is a unique process of profiling the patient. This approach is getting more validity from the science of medicine and now a totally new field of personal medicine is emerging. With more understanding on genetics and gene expressions, the individualisation is likely to get more rational position in the science of Homeopathy. (Details on this concept shall be analysed in later articles).

\section{Conclusion}

The practice of clinical medicine in every medical system is an art as well as science; therefore, we could say that the art and science are complementary in medicine. Different medical systems emerged based on the knowledge existed on that period of time. The redundancy crept in to the science of these systems due inaction to find explanations based on the contemporary knowledge, however the TCAM therapies continued to be scientific on its domain and uses the best artistic approach to understand the diseases and treat the patient scientifically. This is the reason why the popularity of the system is increasing 
in spite of marvellous advances in biomedicine [10]. Sadly, the reductionist science does not recognise most of the basic principles of TCAM therapies, thereby un-utilisation of the huge of clinical evidences. This has led to a situation where the research in these systems is directed to convince its detractors rather than enhancing the credibility of the system. Without substantial evidence on the fundamental principles, applied research findings have limited value and acceptance. Hahnemann codified seven principles around the key concept of similia to make is a complete medical system which would become safe and effective in public health. For centuries, these were not investigated, partly due to limitation of the science, partly due inability of Homeopaths to open the door of investigation with the science as we know at different periods of time. The most controversial of the crucial principles of Homeopathy is the drug dynamisation. Many hypothesis are emerging to understand this principle closely. The xenobiotic concept of biological science, the water memory and carbon bonding concepts mainly based on the structure of the vehicle used to potentise the medicine, nano precipitation, Arndt-Schulz Law, energy transmission concepts are all possible research models to understand this principle. Each of these concepts gives partial exposition to the Hahnemanian concept of drug dynamisation. Understanding the mechanism of evolution of symptoms in drug proving, understanding the patients with more objectivity through gene expression of the individual patient are other major challenges to understand other crucial principles.

Study of disease requires the aid of science. To understand diseases, its course and prognosis, complications etc a student of homeopathy need to know physiology, biochemistry and pathology. When he goes to learn applied medicine, he needs to know more about nano pharmacology, bio physics, gene expressions, gene regulation, molecular genetics etc to understand the pharmacokinetics and pharmaco dynamic of homeopathy. Innovation in the science of homeopathy is the need of the hour and also the route to mainstream the system both for the critics as well its ardent followers. Clarity on the concepts shall guide to better research.

\section{References}

1. Jain MK, Principles of Organic chemistry, $6^{\text {th }}$ Edn, Delhi -7 .

2. Raj Vir Bhalwar (2009) Text Book of Public Health \& Community Medicine, $1^{\text {st }}$ Edition.

3. Samuel Hahnemann (1922) Organon of Medicine, Translated with Preface by William Boericke.

4. (1966) Indian Journal of Psychiatry. Indian Psychiatric Society 8(11): Pp. 58.

5. S Suresh (2012) Collections from the scientific researches in homoeopathy.

6. Rati Ram Sharma. Science of Homoeopathy is beyond contemporary sciences.

7. Vinod D (2016) Shah Fluid Thoughts Water: Structure and Mysticism, Notion Press.

8. Marc Micozzi (2018) Fundamentals of Complementary, Alternative, and Integrative Medicine, $6^{\text {th }}$ Edition.

9. Jesmin Mondal, Ashis Kumar Panigrahi, Anisur Rahman Khuda Bukhsh (2015) Physico chemical and ultra-structural characterizations of PLGA-loaded nanoparticles of Boldine and their efficacy in ameliorating cisplatin induced hepatotoxicity in normal liver cells in vitro. Journal of Innovations in Pharmaceuticals and Biological Sciences 2 (4): 506-521.

10. Eswara Das (2018) The Science and Art of Homeopathy. Journal of Complimentary medicine7(3): 1-4.

\section{Your next submission with Juniper Publishers will reach you the below assets}

- Quality Editorial service

- Swift Peer Review

- Reprints availability

- E-prints Service

- Manuscript Podcast for convenient understanding

- Global attainment for your research

- Manuscript accessibility in different formats

( Pdf, E-pub, Full Text, Audio)

- Unceasing customer service

Track the below URL for one-step submission

https://juniperpublishers.com/online-submission.php 